\title{
The Scheme of Stress Detecting Tools by Using HIR333, GSR and DS18B20 Sensors Based On Microcontroller Atmega 8
}

\author{
Takdir Tamba ${ }^{1}$ and Ivo Zoel Sembiring ${ }^{2}$ \\ 1,2 Department of Physics, Faculty of Mathematics and Natural Science, Universitas Sumatera Utara \\ 20155, Indonesia
}

\begin{abstract}
A human stress detector has been designed with the physiological parameters of stress. Stress is a common respond to the demands of the body. There is a necessity for self adjustment, thus it causes disturbance in body's equilibrium. Nowadays, stress is not only experienced by the elders, but also young people. Stress also affects the condition of the body. When someone is stressed, the body will hold integrated reactions against the stressors. These reactions include the increasing heart rate, fast breathing, and cold sweating. The detector works on the condition of the body by using a GSR sensor to determine the conductivity of the skin, HIR333 to detect changes in heart and body temperature DS18B20, which then compared with the specified parameters.
\end{abstract}

Keyword: GSR, HIR333, DS18B20, stress, stress parameter.

Received 12 March 2019 | Revised [14 July 2019] | Accepted [31 August 2019]

\section{Introduction}

The rapid growth of technology and economy has brought changes to human life. Those changes require human to always compete in life. This situation has gradually caused boredom and pressure, which often lead to stress. The cause behind stress is the difficulty in adjusting oneself to changes.

From many researches regarding stress both in psychological and medical disciplines, stress is always found as a negative contribution towards health [1-2]. This research proves that stress increases the potential of disease infection and the decline in immune system. Another negative impact is the inconvenient feeling when stress is failed to be managed. Thus, the ability to manage stress or stress management skills is highly necessary.

The signs of stress on human include the physical reactions, such as the increased heart rate and cold hand. Stress is the common reaction towards the demand of the body. Those demands are

\footnotetext{
*Corresponding author at: Jl. Bioteknologi No.1 Kampus USU, Medan, Indonesia, 20155

E-mail address: takdir@usu.ac.id
} 
Journal of Technomaterial Physics Vol. 1, No. 2, 2019 | $76-82$

the requirement to self adjustment which in the process, body balance will experience some disturbance.

It is highly suggested to have early detection on stress so the serious treatment can be determined to minimize or stop the stress syndromes [3]. When syndromes are not treated early, they will cause some physical illness such as dizziness, pain, insomnia, or worse, heart attack, stroke, cancer, ulcer, Rheumatoid Arthritis and other diseases.

This problem has then become the reason behind the making of this tool. This tool is expected to guide people in recognizing stress since the early stage to avoid the impacts on their physical health. This tool is created with the combination of electronic, medical and psychological disciplines, where its measurement standard is similar to the psychological measurement scale.

\section{Methods and Scheme}

Stress begins with the alarm reaction towards threats which is seen from the automatic body responds, for examples the increased heart rate followed by the rejection towards stressors (stress trigger), which eventually reach the exhaustion if someone is not capable to survive. Body will form integrated reactions to face a stressor. The cortisol hormone will coordinate whole system in the body (heart, lungs, blood circulation, metabolism and immune system) to react towards the stressor.

That is why when someone is stressed, the heart rate will suddenly increase, respiration is faster and body will activate immune system on the skin, bone marrow and lymph nodes to be on guard. The blood flow will also be reduced and transferred to other priority organs. It will causes skin produces cold sweat and hand temperature decreases. These changes on the body will be caught by the sensor according to the level of the stress.

\subsection{Heart Rate Sensor}

The heart rate detecting sensor used the infrared type HIR333 as the transmitter and photodiode as the receiver [4]. Despite having a long wavelength, the infrared light is not able to penetrate the materials which cannot pass the visible light [5-6]. Thus, the infrared light still possesses the similar characteristics as the visible light.

Photodiode is the diode which reverse flow changes when it receives radiation. The work principle of photodiode is when given a reverse bias, a small current will flow through the diode, which temperature and intensity are dependent to the light on the depletion layer.

\subsection{GSR (Galvanic Skin Response) Sensor}

GSR is a sensor capable of sensing and measuring the conductivity level of skin [7-8], which differ based on the skin moisture or the salinity contained in sweat on the skin. The interesting thing that draws attention is that basically the sweat glands is influenced by the sympathetic 
nerve, hence the change of someone's emotional level will affect the sweat gland in secreting sweats on skin surface. This will eventually affects the skin conductivity level.

\subsection{Temperature Sensor DS18B20}

The temperature sensor DS18B20 has digital version in small size, and the access method is by 1 wire serial [9-10]. This sensor saves microcontroller pin port, because 1 microcontroller pin port can be used to communicate with some other devices. This sensor performs high accuracy level, which is $0.5^{\circ} \mathrm{C}$ on temperature range of $-10^{\circ} \mathrm{C}$ up to $+85 \mathrm{C}$.

a. Possesses a unique 64-bit serial code

b. Operates without external power supply

c. Power supply $3-5.5 \mathrm{~V}$. Obtained from data current

d. Temperature measurement from $-55^{\circ} \mathrm{C}-+125^{\circ} \mathrm{C}$

e. ADC 9 bit resolution

f. Conversion time max to $750 \mathrm{~ms}$

\subsection{HIR333 Infrared Sensor Circuit}

The infrared sensor functions to detect the heart rate through the blood flow in the hand. There are two main blocks in this circuit: heart sensor circuit and the amplifier circuit [11].

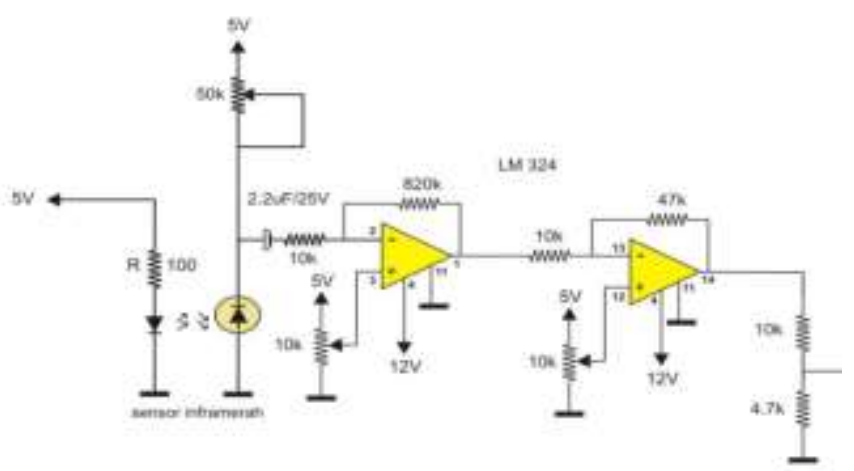

Figure 1. Heart Rate Detector Circuit

On the first op-amp, the amplifier is set to produce the 82 times reinforcement. The second opamp is set to produce 4.7 times reinforcement. Total reinforcement is 385.4 times. Photodiode drained $10 \mathrm{mV}$ upon receiving radiation from the infrared. Based on the circuit above, the output voltage from photodiode can be calculated with this equation:

$$
V_{\text {out }}=G_{\text {total }} \times V_{\text {in }}=385.4 \times 10 \mathrm{mV}=3.854 \text { Volt }
$$

On the circuit above, there is a voltage divider circuit. The divider circuit can be calculated with this following equation: 


$$
\begin{aligned}
V_{\text {out }} & =\left(\frac{R_{2}}{R_{1}+R_{2}}\right) V_{\text {in }} \\
& =\left(\frac{4,7 K}{10 K+4.7 K}\right) 3,854 \text { Volt } \\
& =1.23 \text { Volt }
\end{aligned}
$$

\subsection{GSR Sensor Circuit}

GSR sensor made of cloth and electrode slab were placed on 2 fingers on left hand: middle finger and pointer [12-13].

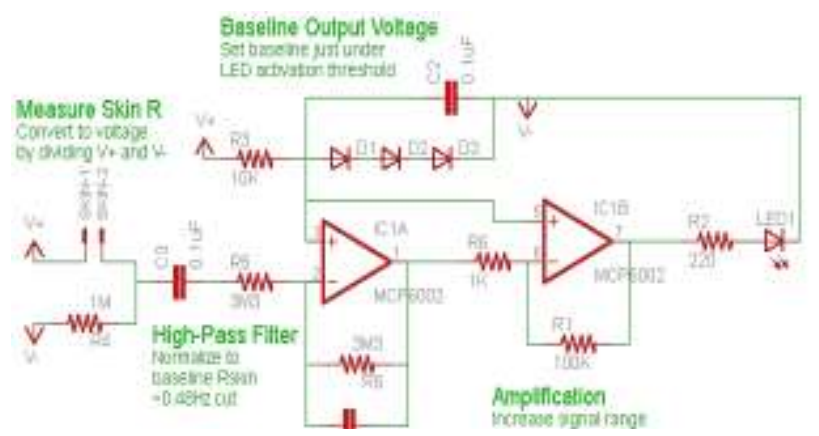

Figure 2. GSR Circuit

Human skin is a fine electric conductor. When the weak electric was sent to skin, the change on skin conduction can be measured. The variables measured are skin resistance or reciprocal, skin conductance.

According to Ohm's law, resistance skin I is equal to voltage (V) is applied between two electrodes on skin, divided with the current through skin (I). The law is stated as follows:

$$
R=\frac{V}{I}
$$

\subsection{DS18B20 Sensor}

Sensor was controlled by microcontroller only at 1 bit, showing the efficient use of port [14-17].

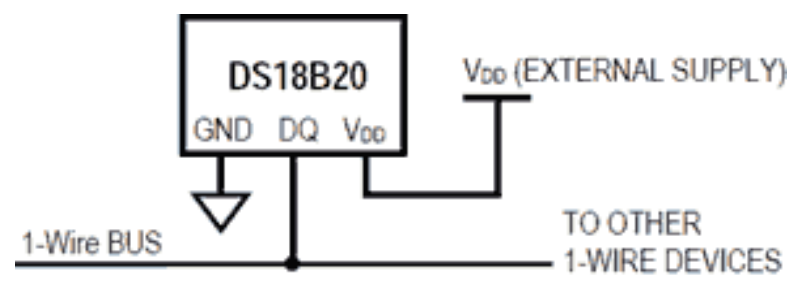

Figure 3. DS18B20 Sensor Circuit

\subsection{TOOLS SCHEME: Block Diagram}

This block diagram is created to learn and understand easier the work method and function of the stress detector: 


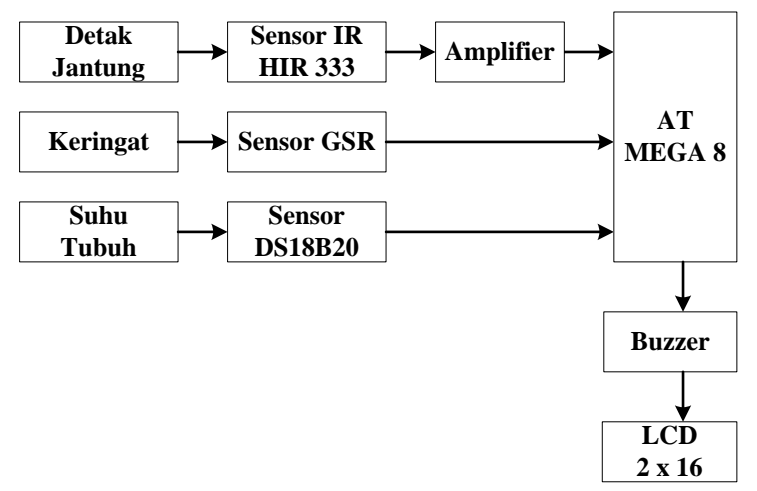

Figure 4. The Block Diagram of the Circuit

\section{Result and Discussion}

The overall result of the scheme is seen in this following figure:

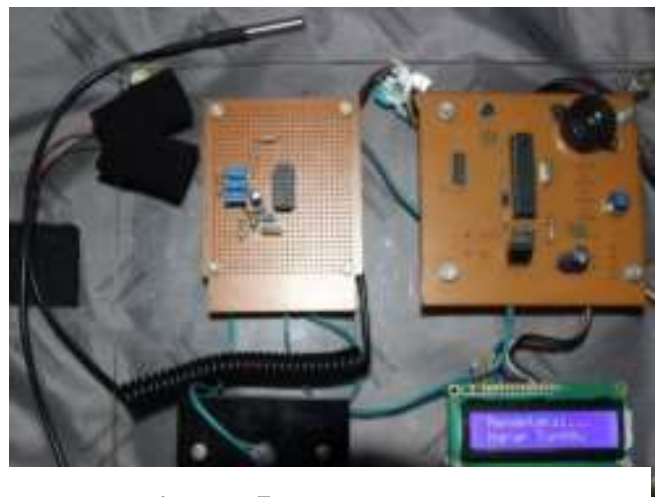

Figure 5. Stress Detector

Table 1. The stress condition and parameter on human

\begin{tabular}{cccc}
\hline \multirow{2}{*}{ Condition } & \multicolumn{3}{c}{ Parameter } \\
\cline { 2 - 4 } & HR $(\mathrm{bpm})$ & GSR (Siemens) & Temperature \\
\hline Normal & $60-90$ & $<4$ & $>35$ \\
Mild Stress & $90-100$ & & $33-35$ \\
Severe Stress & $>100$ & $>6$ & $<33$ \\
\hline
\end{tabular}

\subsection{Overall Tool Test}

The overall tool test was conducted by stringing up all the compulsory components in minimum system ATMega 8, GSR sensor, DS18B20 temperature sensor, and Heart Rate sensor which then programmed with C language by using CV-AVR $3.08[12,18]$.

There were several conditions happened to this tool after the test. The available indications are normal, mild stress and heavy stress. So when the GSR is at 6 and HR is at $92 \mathrm{bpm}$, the indication is mild stress. But on this tool, one parameter is not enough. GSR, HT and temperature data must be compared because our palms will sweat along with the changing emotional condition. 
Table 2. The Result Data of Heart Rate, GSR and DS18B20

\begin{tabular}{cccccc}
\hline No & Name & $\begin{array}{c}\text { Heart Rate } \\
(\mathrm{bpm})\end{array}$ & $\begin{array}{c}\text { GSR } \\
(\text { Siemens })\end{array}$ & $\begin{array}{c}\text { DS18B20 } \\
\left({ }^{\circ} \mathrm{C}\right)\end{array}$ & Result \\
\hline 1 & Teguhta S & 85 & 6 & 35.25 & Normal \\
2 & Putri S. & 82 & 5 & 34.12 & Mild Stress \\
3 & Daniel & 92 & 2 & 36.3 & Normal \\
4 & Desi Rahmanda & 82 & 4 & 34.87 & Mild Stress \\
5 & Hari Saragih & 78 & 3 & 35.27 & Normal \\
6 & Sarvita Simaibang & 76 & 4 & 35.73 & Normal \\
7 & Edo Putra & 80 & 1 & 35.22 & Normal \\
8 & Yuni Sinaga & 75 & 2 & 35.89 & Normal \\
9 & Jhon Victor & 96 & 5 & 35.02 & Mild Stress \\
10 & Citra Damanik & 81 & 6 & 34.08 & Mild Stress \\
\hline
\end{tabular}

When heart rate sensor was not installed to the hand, the output voltage was 0. But when it was installed, the voltage was changing according to the heart beat. When heart pumped the blood to the whole body, the blood volume in left hand's pointer finger increased, causing the light intensity on photodiode decreased and the output voltage turns bigger. This indicated that heart beat can be detected by sensor.

The external light disturbance also disrupts photodiode from obtaining the light from infrared. On the other hand, it is also influenced by the finger thickness. The thicker the finger, the smaller the intensity that photodiode can obtain [19-20]. If the hand position is not exactly between photodiode and infrared, the work method will not be in precision.

\section{Conclusion}

1. The photodiode sensor and infrared HIR333 (heart rate) are able to detect blood vein in human fingers with the error rate of $3.305 \%$.

2. The temperature measurement with DS18B20 sensor performs a very good accuracy rate of $98.59 \%$.

3. The stress detector tool can only be used if object is static and fulfill the inclusion and exclusion criteria.

\section{Acknowledgement}

To the staff of Laboratorium Instrimentasi Digital and Mrs. Dr. Wika Hanida Lubis, Mked(PD), SpPD-Kpsi, FINASIM, Niken R Damanik, S.Ked for the guidance in understanding human stress physiology.

\section{REFERENCES}

[1] J. C. ELizabeth, Buku Saku Patofisiologi Edisi Ketiga, Jakarta: Penerbit Buku Kedokteran EGC, 2007. 
[2] L. Sherwood, Fisiologi Manusia dari Sel ke Sistem Edisi Keenam, Jakarta: Penerbit Buku Kedokteran EGC, 2007.

[3] H. Selye, "Stress and The General Adaptation Syndrome," British Medical Journal, vol. 1, no. 4667, pp. 1383-1392, 1950.

[4] R. Duarte, Pulse Detector Using Infrared Light to Detect a Heartbeat, Columbus: The Ohio State University, 2011.

[5] L. Boccanfuso, E. J. Perez, M. Robinson and J. M. O'Kane, "Collecting Heart Rate Using a High Precision, Non-contact, Single-Point Infrared Temperature Sensor," In International Conference on Social Robotics, pp. 86-97, Springer, Berlin, Heidelberg, 2012.

[6] A. Gupta and B. Thomas, "A New Revolutionary Infrared Life Detection System Using ATMega168," International Journal of Embedded Systems and Applications, vol. 2, no. 3, pp. 117-122, 2012.

[7] T. Westeyn, P. Presti and T. Starner, "ActionGSR: A Combination Galvanic Skin Response-Accelerometer for Physiological Measurements in Active Environments," In 2006 10th IEEE International Symposium on Wearable Computers, pp. 129-130, IEEE, 2006.

[8] Y. Shi, N. Ruiz, R. Taib, E. Choi and F. Chen, "Galvanic Skin Response (GSR) as An Index of Cognitive Load," In CHI'07 Extended Abstracts on Human Factors in Computing Systems, pp. 2651-2656, 2007.

[9] Y. Zhao and Y. Xu, "Temperature Measurement System Based on DS18B20," Modern Electronics Technique, vol. 10, 2008.

[10] M. Chen, M. Chen and C. Qiu, "Design and Realization of Digital Temperature Sensor Based on DS18B20," Modern Electronics Technique, vol. 8, 2008.

[11] M. Tooley, Rangkaian Elektronik Prinsip dan Aplikasi, Jakarta: Erlangga, 2002.

[12] D. Kurniawan, ATMega 8 dan Aplikasinya, Jakarta: PT. ELex Media Komputindo, 2009.

[13] J. Bakker, M. Pechenizkiy and N. Sidorova, "What's Your Current Stress Level? Detection of Stress Patterns from GSR Sensor Data," In 2011 IEEE 11th international conference on data mining workshops, pp. 573-580, IEEE, 2011.

[14] Y. Takahashi, N. Hasegawa, K. Takahashi and T. Hatakeyama, "Human Interface Using PC Display with Head Pointing Device for Eating Assist Robot and Emotional Evaluation by GSR Sensor," In Proceedings 2001 ICRA. IEEE International Conference on Robotics and Automation (Cat. No. 01CH37164), vol. 4, pp. 3674-3679, IEEE, 2001.

[15] H. Millman, Electronic Devices and Circuits, Singapore: Mc Graw-Hill, 1976.

[16] W. Widjanarka, Teknik Digital, Jakarta: Erlangga, 2006.

[17] Z. J. Jun, "Smart Temperature Sensor DS18B20 and Its Application," Instrumentation Technology, vol. 4, pp. 68-70, 2010.

[18] B. Hari, Pemrograman Mikrokontroler dengan Bahasa C, Yogyakarta: Andi Yogyakarta, 2012.

[19] H. Zimmermann, A. Marchlewski, W. Gaberl, I. Jonak-Auer, G. Meinhardt and E. Wachmann, "Blue-Enhanced PIN Finger Photodiodes in a $0.35-\mu \mathrm{m}$ SiGe BiCMOS Technology," IEEE Photonics Technology Letters, vol. 21, no. 22, pp. 1656-1658, 2009.

[20] Chiou, Yu-Zung, Kuen-Hsien Lin, Chen Ying Lieh, and Shou-Yi Hsu, "Design and Fabrication Method for Finger n-type Doped Photodiodes with High Sensitivity for CIS Products," U.S. Patent 6881986B1, April 19, 2005. 